\title{
Universiteit
}

Leiden

The Netherlands

\section{Maternal and paternal thrombophilia: risk factors for perinatal mortality}

Galan-Rosen, A.E.M. de; Kuijpers, J.C.; Rosendaal, F.R.; Steegers, E.A.; Beers, W.A. van; Ponjee, G.A.; Merkus, H.M.

\section{Citation}

Galan-Rosen, A. E. M. de, Kuijpers, J. C., Rosendaal, F. R., Steegers, E. A., Beers, W. A. van, Ponjee, G. A., \& Merkus, H. M. (2005). Maternal and paternal thrombophilia: risk factors for perinatal mortality. Bjog - An International Journal Of Obstetrics And Gynaecology, 112(3), 306-311. Retrieved from https://hdl.handle.net/1887/5062

Version: $\quad$ Not Applicable (or Unknown)

License:

Downloaded from: https://hdl.handle.net/1887/5062

Note: To cite this publication please use the final published version (if applicable). 


\section{Maternal and paternal thrombophilia: risk factors for perinatal mortality}

\section{Agnes E.M. de Galan-Roosen, ${ }^{\text {a Johan C. Kuijpers, }},{ }^{\mathbf{b}}$ Frits R. Rosendaal, ${ }^{\mathrm{c}}$ Eric A. Steegers, ${ }^{\mathrm{d}}$ Wil A. van Beers, ${ }^{e}$ Gabriëlle A. Ponjee, ${ }^{e}$ Hans M. Merkus ${ }^{f}$}

Background Although some paternal components to the predisposition to pre-eclampsia have been demonstrated recently, it is not known whether such paternal factors play a role to thrombophilia-related perinatal mortality.

Objective To compare the paternal and maternal contribution to perinatal mortality.

Study design Data from a prospective registry of perinatal mortality in a Dutch healthcare region were used. Between December 1999 and May 2000, the prevalence of thrombophilia was studied in 74 women with a history of perinatal mortality (female cases) and 54 of their male partners (male cases). Seventy-one healthy unrelated women after uneventful pregnancies only and 66 of their male partners were used as controls.

Setting Obstetric outpatient clinic in a regional hospital (Remierde Graaf Group, Deflt).

Methods Presence of various coagulation abnormalities, hyperhomocysteinaemia and anticardiolipins was investigated.

Results The frequency of antithrombin deficiency (12\% vs $0 \%$ ), increased activated protein C (APC) resistance (32\% vs 6\%), total protein S deficiency (11\% vs 1\%) and elevated factor VIII:C activity (43\% vs $17 \%$ ) was significantly higher in female cases compared with controls. In male cases, the frequency of increased APC resistance was significantly higher compared with controls (22\% vs $0 \%)$. In 30 of the 54 couples with a history of perinatal mortality, more than one thrombophilic abnormality was found (55\%) compared with 10 of the 62 control couples $(17 \%)$.

Conclusion The risk of having thrombophilia is doubled in men who have fathered pregnancies which ended in perinatal death as well as in the mothers of such pregnancies.

\section{INTRODUCTION}

The risk of perinatal mortality in the Western world is $0.5 \%$ to $1 \%$ of children with a birthweight over $500 \mathrm{~g}$. ${ }^{1}$ This may be lowered if risk factors can be detected and adequate preventive measures are undertaken. Maternal thrombophilia is such a risk factor and has been related to pregnancyassociated thrombosis and pre-eclampsia, intrauterine

${ }^{a}$ Department of Obstetrics and Gynaecology, TweeSteden Hospital, Tilburg, The Netherlands

${ }^{\mathrm{b}}$ Department of Obstetrics and Gynaecology, Reinier de Graaf Group, Delft, The Netherlands

${ }^{\mathrm{c}}$ Department of Clinical Epidemiology and Haematology, University Medical Centre, Leiden, The Netherlands

${ }^{\mathrm{d}}$ Department of Obstetrics and Gynaecology, University Medical Centre, Dijkzigt Rotterdam, The Netherlands

${ }^{\mathrm{e} D e p a r t m e n t}$ of Clinical Chemistry, SSDZ laboratory Reinier de Graaf Group, Delft, The Netherlands

${ }^{\mathrm{f}}$ Department of Obstetrics and Gynaecology, University Medical Centre, St. Radboud Nijmegen, The Netherlands

Correspondence: Dr A. E. M. de Galan-Roosen, Department of Obstetrics and Gynaecology, TweeSteden Hospital, P.O. Box 90107, 5000 LA Tilburg, The Netherlands. growth restriction, placental abruption, recurrent miscarriage and late fetal loss. ${ }^{2-10}$ As much as $65 \%$ of those vascular complications may be associated with some form of inherited or acquired thrombophilia. ${ }^{11,12}$

In previous studies, $80 \%$ of the carriers of a thrombophilic genetic defect who experienced 'unexplained' fetal death demonstrated placental thrombosis, infarctions and extensive perivillous fibrin deposition. ${ }^{10}$ In pre-eclampsia, paternal as well as maternal genes, expressed in the fetus and the trophoblast, may play a part. ${ }^{13}$ The aim of our study was to investigate the prevalence of both maternal and paternal thrombophilia in parents who experienced at least one episode of perinatal mortality and compare it to a control group of parents with uncomplicated preceding pregnancies.

\section{METHODS}

During the decade of 1983 to 1992 , a prospective registry of perinatal mortality was performed in the Dutch healthcare region Delft-Westland-Oostland (DWO). ${ }^{14}$

All cases of perinatal death with a birthweight of $500 \mathrm{~g}$ or more - according to the definition of the World Health Organisation (WHO) for standard national perinatal death figures ${ }^{15}$ - were included into the study $(N=239)$. The 
Table 1. Classification of perinatal death.

\begin{tabular}{lcc}
\hline Classification of perinatal death & $\begin{array}{c}\text { Present study } \\
(n=74)\end{array}$ & $\begin{array}{c}\text { Total study } \\
(N=239)\end{array}$ \\
\hline Infection & 6 & 16 \\
Placental pathology & 46 & 127 \\
Maternal immune system pathology & & \\
Blood type incompatibility & 1 & 2 \\
Congenital malformations & 17 & 55 \\
Complications of & 4 & 20 \\
immaturity/prematurity & & 2 \\
Birth trauma & - & 17 \\
Unclassifiable & - & 239 \\
Total & 74 & \\
\hline
\end{tabular}

perinatal mortality rate of the region during that period was 8.25 per thousand. The reliability of these perinatal death figures was studied earlier and proved to be adequate as over $99 \%$ of all cases were registered. ${ }^{16}$

Between December 1999 and May 2000, these women and their male partners were approached by mail. For 59 women, no recent address could be traced, no response was obtained of another 70 and 36 women refused to participate. This left 74 women (female cases) for further study. The perinatal deaths were classified (Table 1) according to the methods as described earlier. ${ }^{14}$ Seven women experienced more than one perinatal death. Among the male partners of these 74 women, 2 men recently died of sudden heart death, 10 were divorced and 8 refused participation, leaving 54 male partners (male cases) for further study.

Seventy-one control women with year of birth between 1950 and 1970 and 66 of their partners were recruited by advertisement as controls. They were included if they had delivered no fetus with malformations, they had no history of perinatal mortality or recurrent miscarriage and were not pregnant at the time of the study. The study was approved by the local medical-ethical committee and all women and their partners gave informed consent.

Blood was collected by venipuncture between 8 and 10 a.m. in all women and partners after overnight fasting. Citrated ( $0.105 \mathrm{M}$ trisodiumcitrate) blood samples were used for the analysis of protein $\mathrm{C}$ activity (PCAct), antithrombin activity (AT) and factor VIII activity (F VIII:C), total protein $\mathrm{S}$ antigen (PSAg) and free protein $\mathrm{S}$ antigen (free PSAg) concentration, activated protein $\mathrm{C}$ resistance (APC-R) as well as DNA analysis for thrombophilia-related mutations: Factor V G1691A (F V Leiden), Prothrombin G20210A and Methylenetetrahydrofolatereductase (MTHFR) C677T.

EDTA blood samples were taken to measure homocysteine concentrations and plasma anticardiolipid IgG and IgM antibodies (ACA-IgG, ACA-IgM). Blood samples were immediately centrifuged at $2000 \times g$ for 20 minutes, snap frozen in small aliquots and stored at $-80^{\circ} \mathrm{C}$.

All functional clotting assays were performed on an Electra 1600C Automatic Coagulation Analyzer (Instrumentation Laboratory, Milan, Italy) PCAct and AT were determined by chromogenic assays (Chromogenix, Milan, Italy). F VIII:C was performed as a two-step clotting assay using factor-deficient plasma of Dade Behring (Marburg, Germany). Anticoagulant response to APC (APC-R) was defined as the ratio of the clotting times obtained in the presence and absence of APC (Coatest APC Resistance, Chromogenix). APC-R was defined to be increased when the sensitivity ratio (SR) was $<1.8$. PSAg was quantitated with specific enzyme linked immunosorbent assays (ELISA; Dakopatts Copenhagen, Denmark). Free PSAg was separated from PS-C4BP complexes by precipitation with PEG 2000. ACA-IgG and ACA-IgM plasma levels were established by ELISA (Quanta lite ACA IgG and IgM, Inova Diagnostics, Netherlands). For the determination of fasting plasma homocysteine levels, high performance liquid chromatography (HPLC) technique was used.

For the molecular diagnosis of $\mathrm{F} \mathrm{V}$ Leiden, the prothrombin G20210A mutant and the C677T MTHFR mutation, DNA was isolated from blood by the QIAamp DNA Blood Mini Kit (Qiagen, Hilden, Germany). Multiplex PCR was performed by amplifying specific sequences of Factor V (F V), prothrombin (F II) and MTHFR genes by multiple primer sets. The PCR products were simultaneously analysed by reverse hybridisation with specific probes for FV Arg506Gln and FII G20210A and C677T MTHFR on a Line Probe Assay (LiPA) in a semi-automated assay. ${ }^{17}$

Data analysis was performed with the Statistical Package for Social Sciences for Windows, version 10.0 (SPSS, Chicago, USA). Numerical data were summarised with means and standard deviations, categorical data with numbers and percentages. Relative risks of perinatal death associated with laboratory abnormalities were expressed as odds ratios, with $95 \%$ confidence intervals according to Woolf. ${ }^{18}$ Adjustment for putative confounders such as age, parity and blood type was performed with unconditional logistic regression. The cutoff levels were the reference values of the laboratory.

Table 2. Population characteristics of women. Values are presented as median [range] or $n(\%)$.

\begin{tabular}{lcccc}
\hline Characteristic & $\begin{array}{c}\text { Female } \\
\text { cases* } \\
(n=74)\end{array}$ & $\begin{array}{c}\text { Female } \\
\text { controls } \\
(n=71)\end{array}$ & $P$ & $\begin{array}{c}\text { OR } \\
(95 \% \mathrm{CI})\end{array}$ \\
\hline Age & $41[32-56]$ & $39[27-50]$ & 0.02 & \\
Parity & $3[2-7]$ & $2[2-4]$ & $<0.001$ & \\
Oral contraceptive use & $18(24)$ & $13(18)$ & 0.42 & $1.4(0.6-3.2)$ \\
\hline
\end{tabular}

* Female cases are women with perinatal death $\geq 500 \mathrm{~g}$. 
Table 3. Thrombophilic factors in men. Values are presented as $n(\%)$.

\begin{tabular}{|c|c|c|c|c|c|}
\hline Thrombophilic factors & Cutoff values & $\begin{array}{c}\text { Male cases } \\
\quad(n=54)\end{array}$ & $\begin{array}{l}\text { Male controls } \\
\quad(n=66)\end{array}$ & $P$ & OR $(95 \% \mathrm{CI})$ \\
\hline AT & $<80 \%$ & $5(9)$ & $1(2)$ & 0.09 & $6.5(0.7-58)$ \\
\hline APC-R & $\mathrm{SR}<1.8$ & $12(22)$ & $0(0)$ & $<0.001$ & n.e.* \\
\hline PCAct & $<70 \%$ & $0(0)$ & $1(2)$ & 1.00 & n.e.* \\
\hline Total PSAg & $<70 \%$ & $1(2)$ & $0(0)$ & 0.45 & n.e.* \\
\hline Free PSAg & $<20 \%$ & $0(0)$ & $0(0)$ & 1.00 & n.e.* \\
\hline F VIII:C & $>150 \%$ & $12(22)$ & $13(20)$ & 0.82 & $1.1(0.5-3)$ \\
\hline Homocysteine & $>15 \mu \mathrm{mol} / \mathrm{L}$ & $4(7)$ & $7(11)$ & 0.75 & $0.7(0.2-2)$ \\
\hline ACA-IgM & $>20 \mathrm{GPL}$ & $3(6)$ & $1(2)$ & 0.33 & $3.8(0.4-37)$ \\
\hline ACA-IgG & $>15 \mathrm{MPL}$ & $5(9)$ & $3(5)$ & 0.47 & $2.1(0.5-9)$ \\
\hline Prothrombin mutation & & $1(2)$ & $1(2)$ & 1.00 & $1.2(0.8-20)$ \\
\hline Factor V Leiden & & $4(7)$ & $1(2)$ & 0.17 & $5.2(0.6-48)$ \\
\hline \multicolumn{6}{|l|}{ MTHFR mutation } \\
\hline Heterozygote & & $30(56)$ & $34(51)$ & \multirow{2}{*}{0.36} & \multirow{2}{*}{$1.4(0.7-3)$} \\
\hline Homozygote & & $5(9)$ & $3(5)$ & & \\
\hline \multicolumn{6}{|c|}{ No. of values outside the cutoff value $\mathrm{e}^{\#}$} \\
\hline None & & $22(41)$ & $45(70)$ & 0.01 & $1(-)$ \\
\hline 1 & & $23(43)$ & $14(22)$ & 0.01 & $1.0(0.1-11)$ \\
\hline 2 & & $8(15)$ & $3(5)$ & 0.01 & $3.3(0.3-40)$ \\
\hline 3 & & $1(2)$ & $2(3)$ & 0.01 & $5.3(0.3-83)$ \\
\hline
\end{tabular}

* n.e. $=$ not estimable.

\# In the controls there were two missing values.

Table 4. Thrombophilic factors in either women or men. Values are presented as $n(\%)$.

\begin{tabular}{|c|c|c|c|c|c|}
\hline Thrombophilic factors & Cutoff values & $\begin{array}{l}\text { Couples of cases } \\
(n=54)\end{array}$ & $\begin{array}{l}\text { Couples of controls } \\
\qquad(n=62)\end{array}$ & $P$ & OR $(95 \% \mathrm{CI})$ \\
\hline $\mathrm{AT}$ & $<80 \%$ & $11(20)$ & $1(2)$ & 0.001 & $15.3(1.9-123)$ \\
\hline APC-R & $\mathrm{SR}<1.8$ & $22(41)$ & $4(7)$ & $<0.001$ & $9.6(3.1-30)$ \\
\hline PCAct & $<70 \%$ & $1(2)$ & $1(2)$ & 1.00 & $1.1(0.1-19)$ \\
\hline Total PSAg & $<70 \%$ & $8(15)$ & $1(2)$ & 0.01 & $10.4(1.3-86)$ \\
\hline Free PSAg & $<20 \%$ & $2(4)$ & $0(0)$ & 0.22 & n.e.* \\
\hline F VIII:C & $>150 \%$ & $28(52)$ & $21(34)$ & 0.09 & $2.1(1.0-4)$ \\
\hline Homocysteine & $>15 \mu \mathrm{mol} / \mathrm{L}$ & $4(7)$ & $9(15)$ & 0.25 & $0.5(0.1-2)$ \\
\hline ACA-IgM & $>20 \mathrm{GPL}$ & $4(7)$ & $2(3)$ & 0.42 & $2.4(0.4-13)$ \\
\hline ACA-IgG & $>15 \mathrm{MPL}$ & $9(17)$ & $7(12)$ & 0.43 & $1.5(0.5-5)$ \\
\hline Prothrombin mutation & & $3(6)$ & $6(10)$ & 0.50 & $0.6(0.1-2)$ \\
\hline Factor V Leiden & & $8^{1}(15)$ & $8^{1}(13)$ & 0.79 & $1.2(0.4-3)$ \\
\hline \multicolumn{6}{|l|}{ MTHFR mutation } \\
\hline Heterozygote & & 37 (69) & $34(55)$ & \multirow{2}{*}{0.38} & \multirow{2}{*}{$1.5(0.6-4)$} \\
\hline Homozygote & & 7 (13) & $12(19)$ & & \\
\hline \multicolumn{6}{|c|}{ No. of values outside the cutoff value $\$$} \\
\hline None & & $8(15)$ & $27(45)$ & $<0.001$ & n.e.* \\
\hline 1 & & $16(30)$ & $23(38)$ & & \\
\hline 2 & & $12(22)$ & $6(10)$ & & \\
\hline 3 & & $12(22)$ & $3(5)$ & & \\
\hline 4 & & $5(9)$ & $1(2)$ & & \\
\hline 5 & & $1(2)$ & $0(0)$ & & \\
\hline
\end{tabular}

\footnotetext{
1 One homozygote F V Leiden mutation.

$*$ n.e. $=$ not estimable.

$\$$ In the controls there were two missing values.
} 


\section{RESULTS}

The characteristics of the women in the study and control groups are presented in Table 2. Adjustment for age led to similar results for all analyses. The use of oral contraceptives (OCs) was not significantly different between the two groups. There was no difference in age between the male cases (median 42, range 35-61) and the controls (median 41, range 31-53).

The distribution of causes of perinatal death investigated in this study was in accordance with the distribution in the total group of 239 cases as described earlier (Table 1). ${ }^{14}$

The frequencies of AT deficiency, total PSAg deficiency, elevated F VIII:C levels and increased APC-R were significantly higher in female cases compared with controls. In our study, $62 \%$ of the female cases and $48 \%$ of the control women had blood type non-O $(P=0.09)$. Neither the prevalence of PCAct deficiency, free PSAg deficiency, hyperhomocysteinaemia, elevated ACA antibodies, F V Leiden mutation, prothrombin mutation nor the MTHFR mutation was significantly different between the two groups.

The percentage of women with one or more thrombophilic factor was 70\% (51/73) compared with 30\% (21/69) in control women (Table 2). A subgroup analysis taking all cases with perinatal mortality due to placental pathology (acute-subacute) into account showed the same statistical significance in all studied thrombophilic factors as in the complete analysis of all cases (women).

In male cases, significantly more frequently increased APC-R was found compared with controls. The differences in the frequency of the other thrombophilia factors were not significant. The percentage of the cases with a thrombophilic factor was $60 \%$ (32/54) compared with 30\% (19/64) in the controls. No difference was found in homozygous MTHFR gene mutation between the cases and the controls (9\% vs 5\%; Table 3 ).

If the results were analysed for couples (results of both partners available and one anomaly in either parent), similar results were found. The odds ratios of the couples were high for abnormally low AT (odds ratio 15, 95\% CI 1.9-123), increased APC-R (OR 9.6, 95\% CI 3-30) and low total PSAg (OR 10, 95\% CI 1.3-86; Table 4).

In 30 of the 54 couples with a history of perinatal death, more than one thrombotic risk factor was found $(55 \%)$ compared with 10 of the 62 control couples (17\%). We found no difference in MTHFR gene mutation in couples of cases compared with control couples (13\% vs 19\%; Table 4).

\section{DISCUSSION}

This study shows that the prevalence of thrombophilia is doubled in both women and men with a history of perinatal mortality. Previous studies that investigated paternal contribution to perinatal death, however, found no contribution of the father concerning thrombophilia. Our results should be interpreted with caution for the following reasons: The number of cases was relatively small and as the perinatal mortality took place more than 10 years ago, many women could not be traced. Nevertheless, we believe that this group is representative for the whole group of 239 patients as the distribution of causes of death was comparable. The relatively small number of cases made us decide not to exclude women using $\mathrm{OC}$ as there was no significant difference between number of pill users in both groups. Furthermore, if we compared the results in the 56 female cases with the 58 controls, both not using OC, the same differences were found. Preston et al. ${ }^{12}$ found no significant difference in fetal mortality in women whose partners had thrombophilia $(n=311)$ compared with that of women whose partners had no known thrombophilia $(n=84)$. This can be explained by the low frequency of fetal loss. Gris et al. ${ }^{9}$ performed a case-control study similar to ours in women and their partners with late fetal loss. They excluded thromboembolic events in the past for both men and women. The absence of an effect of the paternal genotype in that study may well have been the result of this exclusion criterion as a relation between a history of thromboembolic events and perinatal mortality is highly probable.

A paternal role in adverse pregnancy outcome was suggested in a study showing an association between preeclampsia and changing paternity. ${ }^{13}$ Esplin et al. ${ }^{19}$ found evidence for paternal as well as maternal components of the predisposition to pre-eclampsia. Zusterzee ${ }^{20}$ found the glutathione $S$-transferase $\mathrm{Pi} \mathrm{val}^{105} / \mathrm{val}^{105}$ genotype significantly more often in mothers and fathers in cases of preeclampsia. In perinatal death, however, the contribution of this mutation is still unclear.

The fact that some thrombophilic factors, such as F V Leiden, are present in the fetus, that cannot be demonstrated in the mother, ${ }^{21,22}$ also contributes to the concept of some paternal influence on pregnancy outcome. For example, the expression of genetic thrombophilia in the fetus may have negative influences on the fetal and intervillous blood circulation, causing vascular disturbances leading to fetal death. However, this is hypothetic. Also, thrombosis in early pregnancy may lead to disturbances in the microcirculation of developing organ systems possibly leading to congenital malformations in the fetus.

Despite a low prevalence in the normal population for true heritable AT deficiency $(0.02-0.17 \%),{ }^{23} 12 \%$ of the female cases in our study had low AT levels. Elevated F VIII:C levels are more frequently seen in the blood type non-O. ${ }^{24}$ As the distribution of blood type non-O was equally divided between cases and controls, this shows that the association with high F VIII:C levels was pre-existent, and not the result of post-event elevations. Increased APC resistance was highly prevalent in the female cases, however, in only 7 of these 24 cases (29\%) was F V Leiden present and its frequency was not significantly different as compared with that in controls. So in over $70 \%$ the increased APC resistance was not explained by this mutation. 
Table 5. Thrombophilic factors in women. Values are presented as $n(\%)$.

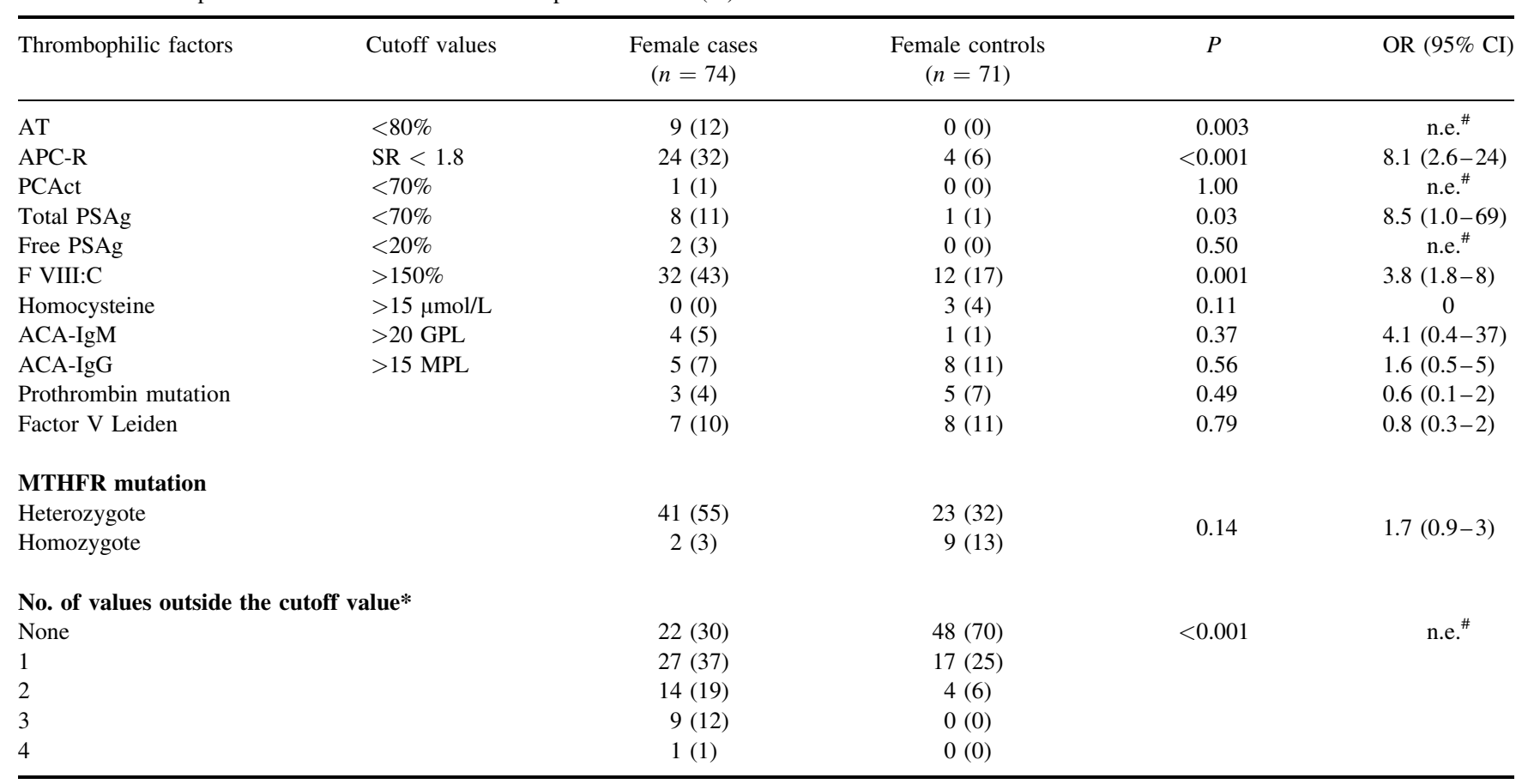

* In the cases there was one missing value, in the controls there were two missing values.

${ }^{\#}$ n.e. $=$ not estimable.

Besides the F V Leiden mutation, however, also acquired risk factors like increased F VIII:C, lupus anticoagulant and OC use are known to induce APC resistance. ${ }^{25}$ This suggests that acquired rather than heritable increased APC resistance is related to perinatal death. Also, new still undiscovered (genetic) clotting factors may play a role. This is in accordance with the raised Factor VIII concentrations, found in our study, as no difference could be demonstrated in the use of OCs. Our findings concerning the prothrombin mutation are not in accordance with studies in which heterozygosity of this mutation has been related to late fetal death. ${ }^{6,10}$

Our findings about the influence of the MTHFR gene mutation are in accordance with the study of Gris et al. ${ }^{9}$ Heterozygosity for the MTHFR gene mutation may act as an additional factor in the presence of other thrombophilic defects as folate requirements are increased and folate stores become partially depleted during pregnancy. It is highly unlikely that folate supplementation was used in the studied period, as in the period 1983-1992, the use of periconceptional folic acid supplementation was not yet recommended as a mass media campaign started in $1995 .^{26}$

Hyperhomocysteinaemia is more often described in cases of early pregnancy loss. ${ }^{4,6}$ This may be an explanation for the fact that we did not find a relation to late fetal and early neonatal loss in our study as pregnancy loss already could have occurred in the first trimester.

The presence of more than one thrombophilic factor was far more frequent in women with a history of perinatal death compared with control women (Table 5).
Combinations of thrombophilic factors like low AT, low free PSAg, low PCAct, increased APC-R and the presence of ACAs are often found in relation to perinatal mortality. $9,11,12$

Our findings of increased prevalences of thrombophilic abnormalities in couples with a child who died perinatally show that both parents may contribute to a hypercoagulable state in both the fetus and the placenta, resulting in fetal loss. As the distribution of causes of perinatal mortality in the study group of 74 cases was comparable with the total group of 239 cases, we conclude that thrombophilia in both men and women is a risk factor for perinatal death. Results of controlled trials are needed to assess the effectiveness of interventions in thrombophilia screen-positive women. So far only the benefit of combined anticoagulant therapy in antiphospholipid antibodies syndrome is demonstrated. ${ }^{27}$ As long as no evidence-based primary preventive methods are available, more intensive monitoring may be indicated as a secondary preventive measure. In cases with a history of perinatal mortality, the thrombophilic status of both parents should be determined.

\section{References}

1. Richardus JH, Graafmans WC, van der Pal-de Bruin KM, AmelinkVerburg MP, Verloove-Vanhorick SP, Mackenbach JP. An European concerted action investigating the validity of perinatal mortality as an outcome indicator for the quality of antenatal and perinatal care. J Perinat Med 1997;25(4):313-324. 
2. Girling J, de Swiet M. Inherited thrombophilia and pregnancy. Curr Opin Obstet Gynecol 1998;10(2):135-144.

3. Vries JIPd, Dekker GA, Huijgens PC, Jakobs C, Blomberg BMEv, Geijn HPv. Hyperhomocysteinaemia and protein S deficiency in complicated pregnancies. Br J Obstet Gynaecol 1997;104:1248-1254.

4. Wouters MGAJ, Boers GHJ, Blom HJ, et al. Hyperhomocysteinaemia: a risk factor in women with unexplained recurrent early pregnancy loss. Fertil Steril 1993;60:820-825.

5. Nelen WLDM, Molen EF van der, Blom HJ, Heil SG, Steegers EAP, Eskes TKAB. Recurrent early pregnancy loss and genetic-related disturbances in folate and homocysteine metabolism. Lancet 1997;350: 861.

6. Brenner B, Sarig G, Weiner Z, Younis J, Blumenfeld Z, Lanir N. Thrombophilic polymorphisms are common in women with fetal loss without apparent cause. Thromb Haemost 1999;82(1):6-9.

7. Foka ZJ, Lambropoulos AF, Saravelos H, et al. Factor V Leiden and Prothrombin G20210A mutations, but not methylenetetrahydrofolate reductase $\mathrm{C677T}$, are associated with recurrent miscarriages. Hum Reprod 2000;15(2):458-462.

8. Arias F, Romero R, Joist H, Kraus FT. Thrombophilia: a mechanism of disease in women with adverse pregnancy outcome and thrombotic lesions in the placenta. J Matern-Fetal Med 1998;7(6):277-286.

9. Gris JC, Quere I, Monpeyroux F, et al. Case-control study of the frequency of thrombophilic disorders in couples with late foetal loss and no thrombotic antecedent - the Nimes Obstetricians and Haematologists Study5 (NOHA5). Thromb Haemost 1999;81(6):891-899.

10. Martinelli I, Taioli E, Cetin I, et al. Mutations in coagulation factors in women with unexplained late fetal loss. $N$ Engl J Med 2000;343(14): $1015-1018$.

11. Kupferminc MJ, Eldor A, Steinman N, et al. Increased frequency of genetic thrombophilia in women with complications of pregnancy. N Engl J Med 1999;340:9-13.

12. Preston FE, Rosendaal FR, Walker ID, et al. Increased fetal loss in women with heritable thrombophilia. Lancet 1996;348(9032):913916.

13. Lie RT, Rasmussen S, Brunborg H, Gjessing HK, Lie-Nielsen E, Irgens LM. Fetal and maternal contributions to risk of pre-eclampsia: population based study. BMJ 1998;316(7141):1343-1347.

14. Galan-Roosen AE, Kuijpers JC, Straaten PJCvd, Merkus JMWM. Evaluation of 239 cases of perinatal death: using a fundamental classification system. Eur J Obstet Gynecol Reprod Biol 2002;103:37-42.
15. WHO. International Classification of Diseases, 10th edition. Geneva: WHO, 1992.

16. Galan-Roosen AE, Kuijpers JC, Oei YB, van Velzen D, Mackenbach JP. Discrepancy between results of registration of perinatal cause of death by the CBS (Central Bureau of Statistics) and by personal studies in the Delft-Westland-Oostland region. Ned Tijdschr Geneeskd 1997;141(5):237-240.

17. Leyte A, Smits PH, van Straalen JP, van Doorn LJ, Quint WG. Automated, simultaneous detection of the factor V Leiden and prothrombin $(\mathrm{G} 20210 \mathrm{~A})$ variants using multiplex PCR and a line probe assay. Thromb Haemost 2000;83(2):354-355.

18. Woolf B. On estimating the relation between blood group and disease. Ann Hum Genet 1955;19:251-253.

19. Esplin MS, Fausett MB, Fraser A, et al. Paternal and maternal components of the predisposition to preeclampsia. $N$ Engl J Med 2001;344(12):867-872.

20. Zusterzeel PLM. Biotransformation enzymes and oxidative stress in preeclampsia. Thesis, Catholic University Nijmegen, 2001.

21. Dizon-Townson DS, Meline L, Nelson LM, Varner M, Ward K. Fetal carriers of the factor $\mathrm{V}$ Leiden mutation are prone to miscarriage and placental infarction. Am J Obstet Gynecol 1997;177:402-405.

22. Thorarensen O, Ryan S, Hunter J, Younkin DP, Factor V. Leiden mutation: an unrecognized cause of hemiplegic cerebral palsy, neonatal stroke, and placental thrombosis. Ann Neurol 1997;42(3):372-375.

23. De Stefano V, Finazzi G, Mannucci PM. Inherited thrombophilia: pathogenesis, clinical syndromes, and management. Blood 1996; 87(9):3531-3544.

24. Kamphuisen PW, Lensen R, Houwing-Duistermaat JJ, et al. Heritability of elevated factor VIII antigen levels in factor V Leiden families with thrombophilia. Br J Haematol 2000;109(3):519-522.

25. Walker ID. Thrombophilia in pregnancy. J Clin Pathol 2000;53(8): 573-580.

26. De Walle HE, de Jong-van den Berg LT, Cornel MC. Periconceptional folic acid intake in the northern Netherlands. Lancet 1999; 353(9159): 1187.

27. Rai R, Cohen H, Dave M, Regan L. Randomised controlled trial of aspirin and aspirin plus heparin in pregnant women with recurrent miscarriage associated with phospholipid antibodies (or antiphospholipid antibodies). BMJ 1997;314(7076):253-257.

Accepted 17 June 2004 